- благодаря визуализации занятости водителей быстро подбирать необходимый транспорт.

В ходе внедрения программы возможна доработка по запросу заказчика.

Список литературы:

1. http://www.dvgk.ru/ru/posts/press/nergres

2. http://museum.rao-esv.ru/power_facilities/168/

3. Официальный справочник Microsoft Visual Studio C++ [Электронный ресурс]// URL: https://msdn.microsoft.com/ru-ru/library/3bstk3k5.aspx

\title{
Разработка электронной регистратуры «Горизонт»
}

\author{
Батян А.А., студент, \\ Технический институт (филиал) \\ Северо-Восточного федерального университета, \\ 2. Нерюнгри \\ E-mail: mineski1337@gmail.com
}

Научный руководитель: к.т.н., доцент Похорукова М.Ю.

Ни для кого не секрет, что оптимизация рабочего процесса и повышение продуктивности сотрудников положительно сказывается на экономических показателях предприятия. Этих целей можно достичь различными способами, но в современных реалиях одним из самых простых и эффективных путей развития предприятия является автоматизация его инфраструктуры с использованием информационных систем. Руководствуясь этими задачами и принципами, администрация по управлению персоналом ОАО ХК «Якутуголь» приняла решение внедрить в регистратуру комплекса «Горизонт» автоматизированную информационную систему. Такая система представляет собой совокупность программных и аппаратных средств, предназначенных для управления информацией и автоматизации рутинных действий на предприятии.

Перед тем как начать проектировать и разрабатывать систему, необходимо выявить задачи, подверженные автоматизации, а также уровень и состав информационно-технической базы. В результате проведенного исследования необходимая информация была собрана. Регистратура СП «Горизонт» в рамках выполнения своих главных задач должна поддерживать следующие основные функции:

- учет сотрудников комплекса и их квалификации;

- составление графиков посещения процедур клиентами комплекса;

- подсчет стоимости препаратов и процедур;

- учет посещений клиентов;

- составление смет и отчетов для организаций, чьи сотрудники проходили лечение в оздоровительном комплексе.

С точки зрения разработчика, данные задачи можно автоматизировать с помощью внедрения в структурное подразделение информационной системы на основе СУБД и 
приложения для простой и комфортной работы сотрудников комплекса с данной СУБД.

В целях выполнения следующего этапа проектирования, была собрана информация о составе программной и аппаратной технической базы структурного подразделения. На данный момент информационное обеспечение комплекса включает в себя:

- 2 персональных компьютера на базе процессора Intel Core 2 Duo с 2 Гб оперативной памяти, объединённых в локальную сеть;

- Пользовательское окружение: OC Microsoft Windows XP SP2;

- Основная среда электронного офиса: Microsoft Office 2007;

- Основная СУБД, используемая в структурных подразделениях предприятия: Microsoft SQL Server.

Так как доступ к информационной системе должен осуществляется с обоих компьютеров комплекса и основным окружением пользователя является ПО корпорации Microsoft, было принято решение о разработке клиент-серверного приложения электронной регистратуры на базе СУБД MS SQL Server, c использованием среды разработки Microsoft Visual Studio. Использование данной связки позволяет легко и эффективно внедрить приложение в пользовательскую среду без необходимости установки на клиентские компьютеры дополнительного проприетарного ПО. Microsoft Visual Studio была выбрана в качестве среды разработки по причине наличия в базовой версии всех необходимых для внедрения компонентов, а именно:

- компилятор C++ кода для исполнения на х86-64 компьютере под управлением OC Windows;

- библиотеки классов и средства проектирования графического пользовательского интерфейса;

- библиотеки классов для работы с СУБД MS SQL Server;

- библиотеки классов для интеграции приложения с Microsoft Office.

Список литературы:

1. Избачков Ю.С., Петров В.Н. Информационные системы: Учебник для вузов Ю.С. Избачков, В.Н. Петров. - 2-е изд. - СПб.: Питер, 2006. - 656 с.

2. Дейт К. Дж. Введение в системы баз данных - 7-е изд. - Вильямс, 2001. - 1072 c. 